\title{
Health Protection in Prison, Between Equivalence of Care and Less Eligibility
}

\author{
Daniela Ronco \\ University of Torino
}

\begin{abstract}
The article presents some reflections resulting from three different researches conducted by the author on the issues that revolve around the protection of health in Italian prisons, with particular reference to the principle of equivalence of care between inside and outside, sanctioned by the prison healthcare reform. The approach used, the qualitative contributions of which are presented here, has made it possible to highlight the impediments to the implementation of this principle in the prison context, for both cultural and structural reasons. On one hand, the power dynamics and conflicts that characterise every total institution have a significant impact on relations (between prison staff and healthcare professionals, as well as between healthcare professionals/prison staff and prisoners), while the widespread unsanitary nature of prison structures has an impact on daily life and on the level of affliction inherent in the condition of imprisonment. The debate on prisoners' health is therefore situated within the broader frame of the functions of punishment and on the political and cultural aspects of punitiveness, reflecting particularly on the opposition between less eligibility and the principle of equivalence of care.
\end{abstract}

Keywords: prisons, prisoners' rights, prison healthcare, equivalence of care, prison medicine

DOI: $10.7176 /$ RHSS/11-11-08

Publication date:June $30^{\text {th }} 2021$

\section{Afflictive culture of punishment and health protection}

The function of social control exercised by medicine ${ }^{1}$ reaches its peak within total institutions, where expectations in terms of role and interactions undergo a profound restructuring. The healthcare professional who enters a total institution to carry out his profession within a context of limitation of personal freedom inexorably assumes a level of power that is potentially much greater than in ordinary interactions.

If the total institution is, specifically, a prison, the surplus of power held by the healthcare professional is joined by the influence of the punitive culture and the disciplinary mandate that typically characterise the prison environment. The healthcare professional finds himself having to operate under the influence of both his professional mandate to provide care and the instances of security and discipline typical of the total institution (Pont J., Stover H., Wolff, 2012). The result is an ambiguity of role characterised by conflicting drives that are not easy to reconcile (Ronco, 2014), at least in the initial stage. Over time, however, we are likely to see a process of institutionalisation. The prisonization (Clemmer, 1941) affect all those who find themselves within the prison environment and have an impact which, after initial astonishment at the unusual practices, leads to a cultural assimilation whereby violations of rights (including privacy, for example) and breaches of professional ethics tend to be perceived as normal (Vianello, 2018, p. 79). This is why, given that the institutionalisation of the role of the prison doctor is much more pronounced when they work exclusively in prison, it is widely recommended that they continue to practise also outside this context (Niveau, 2007), in order to counteract the process of acclimatisation to prison rules. (White, Jordens, Kerridge, 2014).

Institutionalisation mainly affects two aspects of the principle of equivalence of care (which are obviously interrelated): autonomy and the doctor-patient relationship. In the first case, there is a limitation of the autonomy of both the patient imprisoned and the healthcare professional, both of whom are confined by the demands of security and the organisation of everyday life in prison. These include, as far as the prisoner is concerned, freedom of choice of doctor and treatment, informed consent, limitations of movement and protection of privacy, and, as far as the healthcare professional is concerned, consideration of non-medical factors when assessing which treatments to prescribe ${ }^{2}$, or, more generally speaking, the influences exerted by the "non-excluded third party" (Ronco, 2018, p. 35), i.e.: the prison administration.

But it is in the doctor-patient relationship that we see the greatest impact of prison regulations in terms of redefining the symbolic boundaries of interaction. Like all the relationships established between those who find themselves in the prison environment, the relationship between doctor and patient is characterised by widespread transversal mistrust ${ }^{3}$. If, on one hand, the imprisoned patient expresses reluctance to trust a healthcare

1 The subject is extensively dealt with in literature. See, in particular, the classic contribution by Conrad and Schneider (2010).

${ }^{2} \mathrm{~A}$ typical case is the incidence of the variable of the end of the sentence among the factors that influence the choice of treatment, for addiction for example (Bertolazzi, Zanier, 2018)

${ }^{3}$ In the words of Vianello (2018, p. 77), "the organising principle of prisons, that of mistrust, not only pits staff against inmates, but also pits inmates against each other, and staff against other staff'. 
professional whom he has not chosen and whom he sees as being on the side of the institution, towards which some form of resistance and opposition remains, on the other hand, the healthcare professional frequently uses the rhetoric of simulation (Sim, 2002; Neisser, 1977) when describing conversations and encounters with imprisoned patients. Diffidence and mistrust between doctor and patient are often more or less directly indicated as the main feature of the exercise of the right to health in prison, both by healthcare professionals and prisoners. ${ }^{1}$

It is in this scenario that a situation of less eligibility, which pervades prison culture and proposes an idea of punishment that envisages prison conditions below the minimum standards guaranteed outside ${ }^{2}$, also extends to the sphere of the protection of prisoners' health (Ronco, 2018). Discussions that reiterate the inappropriateness of guaranteeing a series of services normally acknowledged to free individuals (the lack of importance attributed to the concept of prevention, etc.) can therefore be interpreted as a manifestation of the punitiveness that characterises punishment in the broad sense and of the disciplinary role that medical practices play within prison. In the words of Pavarini, "for a long time we were lulled by a beautiful fairy tale - soothing, perhaps, our collective guilt - of a modern world that would overcome the cruelty of the tortures and corporal torments reserved for the lower classes, to adopt a criminal regime 'limited' to the subtraction of time and freedom without aggression on the body [...] incontrovertible documentation shows, however, that the deprivation of liberty that we inflict with imprisonment is, in actual fact, a surviving form of corporal punishment that generates not metaphysical but extremely physical suffering: it is a deliberate pursuit of affliction not only of the spirit, but of the body, to the point of reducing prisoners' life expectancy" (Pavarini, 2003, pp. 11-12).

The tendency of the punitive culture to invade the protection of the right to health can also be seen in what prison sociology has defined in terms of tension between rights and benefits (Salle, Chantraine, 2009). Work and other treatment activities, alternative measures to prison, affectivity and, last but not least, health protection, tend to be considered more as benefits granted under certain conditions than as rights to which one can legitimately aspire. In the Italian context, the tension between rights and benefits stems largely from the reward-based approach taken by the prison system as reformed in 1975, which, with the aim of bringing peace to prisons after the season of riots, made access to alternative measures conditional to the presence of a series of requirements demonstrating the prisoner's cooperative and tamed spirit. In other words, rewards become a tangible manifestation of the disciplinary nature of the prison institution. The mechanism of rewarding, typically of the granting of alternative measures, tends to extend and be applied to daily life in prison as a whole, also conditioning access to the right to health, which, like any other right in prison, tends to be perceived as a benefit rather than a right, as often emerges from prison culture and rhetoric.

\section{Research}

\subsection{Methodology}

The reflections stem from three researches carried out by the Author in the last 10 years in the Italian prison system, aimed at collecting (through questionnaires, interviews and focus groups with prisoners, prison officers and doctors) the different frames and narratives about health, illness and medicine inside prison. In particular, the first research was realised with a questionnaire administered to 1228 people (833 detainees, 189 health professionals, 169 prison officers, 11 governors, 26 prison educators) in 12 Italian prisons. The second study was carried out through a qualitative methodology (focus groups and semi-structured interviews) involving 196 people in 9 Italian prisons, in particular: 90 health professionals, 30 prison officers and governors, 76 detainees. The third research was realised through a questionnaire submitted to the leadership roles (medical and prison staff) of 81 prisons.

The results support the idea of less eligibility as a premise preventing a whole fulfilment of the equivalence of care principle: prison doctors' involvement in a disciplinary and control frame and practices, together with the appalling structural conditions, pose a major risk for prisoners' physical and mental health.

\subsection{The material nature of prisons}

Various national and international reports on the reality of detention ${ }^{3}$ have long highlighted the extreme

\footnotetext{
1 The subject is wide-ranging and we can only touch briefly on it here, but we need to consider how the broader phenomena of the progressive managerialisation and corporatisation of the healthcare system have also had a significant impact on the role and working environment of doctors, questioning their professional freedom and independence when they impose the use of economic and managerial criteria (as a priority over professional criteria) when deciding which treatments and therapies to adopt (Neri, Spina, Vicarelli, 2020). The effects of systemic changes in healthcare include a breakdown in the relationship of trust between the (family) doctor and the patient, with the former being "increasingly perceived as having insufficient knowledge and organisational support, or even seen as an unnecessary step towards direct access to specialist services" (Ingrosso, Mascagni, 2020, p. 168).

${ }^{2}$ As we know, the application of the principle of less eligibility to the context of the prison environment is a subject addressed in particular by Rusche and Kirchheimer (1939).

3 At European level, for example, the European Committee for the Prevention of Torture regularly publishes its reports online on the website http://www.cpt.coe.int/en/
} 
degradation of most prison facilities, the general unsanitary conditions (Mosconi, 2005) of the spaces and the lack of hygiene, which characterise both cells and common areas and have a significant impact on the health of both prisoners and staff. ${ }^{1}$

A first recurring aspect, in the words of many health professionals questioned on the elements of differentiation between the provision of a healthcare service inside and outside prison, revolves around the structural and material aspects of the prison institution.

Cases of scabies and dermatomycosis, contact diseases, have increased. Let's hope they all agree to be vaccinated for flu otherwise it will be a disaster. AIDS makes headlines, but AIDS is a venereal disease and officers are careful about promiscuity. The problem is contact diseases that spread like wildfire, with impressive speed. On top of that, diseases like scabies are infectious before the signs appear on the skin. It's hard to maintain hygiene levels in the cells, especially with overcrowding, which prevents a healthy environment. Then there is the problem that those affected have to be isolated, and this creates big problems for the daily life of the inmates. Pathologies of this kind have not been this widespread since the early 90 s.

Renowned French doctor Daniel Gonin (1991) was among the first to highlight the numerous pathogenic effects of prison in detail: damage to eyesight, mainly due to the inability to see far ahead, because of the walls that constantly surround prisoners; damage to the digestive system, due to the diet, which dieticians say is often incorrect, and due to the stress caused by the prison environment in general; dermatological damage, due to poor hygiene; damage to the respiratory system, due to the fact that, partly due to overcrowding in most prisons, prisoners live in close contact with each other and in closed, cramped spaces. Such descriptions are frequently given by health service users when describing life behind prison walls.

"The food is scarce and substandard; the tap water is disgusting. I doubt if it's even drinkable, but prisoners like me who don't receive visits from families and don't have any money are forced to drink it, and that water is definitely not good for our health".

(prisoner)

"The structure is dilapidated, the metal is rusty everywhere, the medical areas are totally... non-existent, and those we have been created in place of other things that were used for anything but medical purposes, and the organisation of everything is extremely poor.

It rains in the cells, when it rains, it rains in the cells"

(focus group - prisoners)

Another recurring aspect, in the words of the various people involved in the research, is the impact of the prison structure and everyday life in prison on mental health. Psycho-physical handicaps (Gallo, Ruggiero, 1989) caused by imprisonment are often reported as particularly frequent and afflictive, both by prisoners and by healthcare professionals.

"Now finding myself imprisoned and with no affection from my family I have developed anxiety and suffer from panic attacks. I take pills to sleep, without improving my mental state, and my body is more relaxed when I work, instead of lying in bed lazing around, because my mind thinks about my son and my partner outside, but here it's like a stalemate, you're suspended and if you don't work, as I said, or have other outlets, you get sick, like me, with anxiety and panic."

(prisoner)

Concato and Rigione (2005), in particular, have illustrated and argued that there is a general malaise common to all those who find themselves in prison (both prisoners and staff alike), which has both a physical and psychological nature and is attributed primarily to the situation of deprivation of liberty or to particularly delicate and emotionally challenging working conditions, but also to the specific structural conditions of penal institutions.

\subsection{Transversal diffidence and mistrust}

The ambiguity between the exercise of care and disciplinary power has characterised prisons since their inception (Sim, 1990). In this context, there is a wide gap between the principles enshrined in national and supranational regulations (above all, the equivalence of care) and medical practices, which often reflect the more general afflictive culture of punishment (Saponaro, 2018). The risk of institutionalisation of healthcare professionals is high and the interference by the prison administration is frequent and, to a certain extent, inherent in the structuring of relations in prison. So it becomes almost inevitable to think that the doctor-patient relationship is different from the way it is outside, and that the imprisoned patient must have access to a more limited health service, in complete harmony with the application of the principle of less eligibility. More generally, sociological research carried out in prisons has clearly shown how the disciplinary vocation and the

1 The levels of well-being and risk factors perceived by both prisoners and prison officers (cf. Ronco, 2013, p. 36 et seq.) are among the most widely used indicators to measure the quality of life in prisons (Van der Helm, Stams, Van der Laan, 2011; Ross, Diamond, Liebling, Saylor, 2008) 
focus on control and security constitute an insurmountable limit to the protection of rights inside prisons, which risks being nothing more than an illusion (De Galembert, Rostaing, 2014).

On this subject, the healthcare professional is required to draw up various reports that have an impact on the course of detention (e.g., health reports for granting alternative measures for medical reasons) or on the way detention is experienced on a daily basis (transfers to clinical centres, access to special dietary regimens, even changing mattresses, for example). The prison system and the consequent restrictions on freedom imply that the healthcare professional has control over everyday life, which is controlled by the individual outside prison. The possibility to choose your own doctor, to have access to private healthcare, and even to organise your own space and daily activities in a certain way, are denied to prisoners, and this undoubtedly affects the relationship of trust between doctor and patient. Expressions of mistrust frequently emerge, in both directions, from the research conducted. On one hand, the imprisoned patient often expresses mistrust towards the healthcare professional and the health service as a whole.

"The biggest worry in a prison is definitely the impossibility to receive proper treatment for illnesses present before entry into the institution."

(prisoner)

"I think there should be better organisation by the few forces present. Above all, the inmates should be made aware of their health, informed properly after a meeting and given a medical certificate, the same as on the outside, telling them what treatment was prescribed on the day of the visit and for how many days, so that they can hold the doctors accountable, if the treatment and the pathology turn out to be wrong, which is not the case today, because you see a different doctor every time and, if they get the treatment wrong, they simply blame it on one of the other doctors."

(prisoner)

Many prisoners also see healthcare professionals as being deeply prejudiced against imprisoned patients. The prejudice of "simulation" is another characteristic feature of the relationship between the healthcare professional and the imprisoned patient, which differentiates it from the outside world. It reflects the role of the health professional intrinsically linked to the need for security.

"There is a lot of prejudice towards inmates by healthcare professionals (according to whom, all the prisoners fake their illnesses), so the diagnoses tend to be biased and not be based on inmates' real state of health. There is a need for greater accountability in the formulation of medical reports to the supervising magistrates and in obtaining alternative measures for medical reasons."

(prisoner)

"Sometimes the nurses don't take us into consideration, if we ask for help for some medical problem their answer is: you always get sick in here, and they always get fed up and say that we are pretending."

(prisoner)

The term simulation is a recurring mantra among healthcare professionals. It is an expression of the prison culture, which unites security, treatment and healthcare professionals and seems to be the pivot around which the transversal mistrust between prisoners and staff revolves. In many cases, the healthcare professionals bring it up and describe it openly:

"There is a lack of freedom, right? Which is what a prisoner wants. What motivates a prisoner more than anything else is to get out of prison, so this is also one of the parameters to be considered, in the sense that we often do not realise, but also, as healthcare professionals, we are manipulated from this point of view. Prisoners, the majority of them anyway, I mean, I'm generalising here, aim to get out of prison and they are capable of doing anything to achieve this, simulation, whatever you like, trying to get work." (doctor)

"Prisoners try to manipulate everything in order to get out. So health for them becomes "losing their health" or simulating the loss of health. It becomes a way of getting out of prison, so you have to work twice as hard, to assess the person and understand whether their symptoms are real or not. So there is this double aspect that doesn't exist outside. Outside if someone is sick, they're sick, without a shadow of doubt. Here it's a case of, is he or isn't he? And sometimes we run the risk of underestimating cases that have a certain value, a validity, because so many people pretend to be ill." (nurse).

(focus group - healthcare professionals) The prejudice of simulation encompasses the peculiarity of the operator-user relationship in the prison healthcare service. It specifically characterises the professional medical culture and seems to reflect the institution's restrictions on the role of healthcare professionals, affecting their professional independence.

\subsection{The healthcare professional, between professional independence and institutionalisation processes}

The total institution requires a specific interpretation of the principle of independence that characterises the exercise of the medical profession. The following testimony helps understand this:

"In my opinion, health cannot be separated from security, because the prison doctor is halfway between a doctor and an officer. [...] It's not easy to train a prison doctor because he has to be trained in the field, but then he has 
to have special skills too; there are people who are not suited to working here."

Institutionalisation sometimes emerges in conversation, reflecting the correspondence between the professional culture of doctors and prison culture as a whole. However, apart from the more or less accentuated inclination of healthcare professionals to respond to the demands of control, the structural and organisational issues of the prison often require choices that limit the doctor's professional independence. A frequently mentioned example is that of external examinations prescribed by the healthcare professional.

"The problem is often not so much about the medical service as it is about requesting a specialist visit, waiting times and sending the prisoner to an external facility, but this problem depends largely on the availability of Ministry of Justice escorts."

(doctor)

From the point of view of internal organisation and use of resources, the interviewees often reported an increase in requests for external specialist visits, due to the presence of numerous prisoners suffering from pathologies requiring specialist interventions (and, presumably, also due to the frequent recourse to defensive medicine within the prison context). However, the resources for organising translators for hospital visits are often unavailable because of the need to give precedence to translations in court and for transferrals towards other institutions for various reasons.

The result of this mechanism, as reported by many of those interviewed, is that either visits are not requested directly because it is known that they cannot be carried out due to the lack of vehicles and manpower necessary for escorts, or that visits to local hospitals are booked in large numbers but many of them are cancelled at the last moment. This is a classic example of a variable outside the doctor's professional independence that often influences the exercise of his profession, specifically the decision whether or not to prescribe an external visit, which has to take into account the inmate's inability to travel independently and therefore requires the intervention and involvement of the prison institution for organisational matters.

Ultimately, aspects that are strictly cultural intersect with structural matters inherent in the total institution and both contribute to limiting the freedom and independence prescribed by the Code of Medical Ethics, questioning compliance with the principle of equivalence of care enshrined in the prison health reform and the aforementioned article 40.3 of the European Prison Rules, according to which "Prisoners shall have access to the health services available in the country without discrimination on the grounds of their legal situation." (Recommendation Rec(2006)2 of the Committee of Ministers to member states on the European Prison Rules).

\section{Revisiting the principle of equivalence of care in the framework of the protection of human rights in prison}

The principle of equivalence of care is at the heart of the national and supranational regulations that guide the provision of healthcare in prison. The international guidelines of the United Nations and the World Health Organisation, in line with the recommendations of the Council of Europe, define it as the minimum standard of healthcare in prison, and the legislation of many countries has adopted it. Being a minimum standard, it should not be understood as the ideal to be pursued (Jotterand, Wangmo, 2014), but rather as a starting point. This interpretation implies that the assessment should not merely concern equal access, but the result achieved (Charles, Draper, 2012). As highlighted by Lines (2006), to stop at the acquisition of standards equivalent to those outside, without taking into account the surplus of needs that we find inside prisons, represents a risk in at least two senses. On one hand, in terms of violation of prisoners' human rights, as countries have an obligation to guarantee the health of the people in their custody. On the other, there is a risk of failing to fulfil their mandate to protect the public health of the communities to which they will sooner or later return.

It is in this scenario that a specific reflection on the equivalence of care has developed in the interpretative framework that has been proposed in Rawlsian terms (Daniels, 1981). As we know, Rawls proposes a model of equal distribution of main social assets and, according to the author, this is possible only if it benefits those most disadvantaged. In other words, distribution can only be considered equal if it takes into account the initial conditions of disadvantage (Rawls, 1971).

It is necessary to consider that a principle of equivalence of care which focuses solely on the availability of treatments equivalent to those outside is not sufficient to meet the specific health needs of the prison population. It is therefore necessary to acknowledge that, in order to ensure that prisoners have prompt and proper access to healthcare services, it is necessary to increase the availability of treatments inside prison (Exworthy et al, 2012; Gainotti, Petrini, 2020, p. 152).

The distinction, therefore, is between equivalence of access and equivalence of outcome. Equivalence in the sense of equal access to care concerns the organisation of services: what, how and by whom they are provided. The reorganisation of prison medicine in Italy (Legislative Decree 230/99, which came into force with the Prime Ministerial Decree of 1 April 2008) is part of this framework, which, in providing for the transfer of jurisdiction from the Ministry of Justice to the Ministry of Health, has affected the reorganisation of provision of the service. 
This meaning can be considered as the minimum standard. Equivalence of care in terms of outcome, on the other hand, focuses on the extent to which the aims of equality are achieved or otherwise. The latter perspective of analysis is far more interesting from a sociological point of view, which is attentive not only to the functions expressed by legislation, but above all to its impact in the social field.

The prison context offers a particularly interesting cross-section from this point of view, for two reasons. On one hand, it often facilitates the first contact with the healthcare system for social groups that, for various reasons, tend to remain distant from it. At the same time, the social inequalities that often lie at the root of the criminalisation processes that lead to imprisonment tend to coincide with the social inequalities that determine different access to the right to health (Lines, 2006).

It is in this sense that the correction of the structural disadvantages underlying the greater needs expressed by the prison population requires greater attention than outside. This assertion can but prove highly controversial if placed within the legislative framework of the prison culture, where, as highlighted in the first part of this text, the reference to the afflictive and punitive function of prison often overlaps with the provision of the right to health, and the boundaries between the enforcement of the sentence and access to health become blurred. So, the challenge remains to provide new answers to the conflict between less eligibility and equivalence of care. The recent experience of Covid in prisons calls for a more far-reaching reorientation of health and prison policies, which must go beyond the logic of emergency management and focus primarily on prevention and on a comprehensive and attentive response to prisoners' health requirements.

\section{References}

Bertolazzi, A., Zanier, M.L. (2018). The discretionary treatment of drug addiction in prison. Salute e Società, XVII (1), 59-72

Charles, A., Draper, H. (2012). Equivalence of care in prison medicine: is equivalence of process the right measure of equity? Journal of Medical Ethics, 38, 215-218

Clemmer, D. (1941). The Prison Community. Boston: Christopher Publishing House.

Concato, G., Rigione, S. (ed.) (2005). Per non morire di carcere. Milano: Franco Angeli.

Conrad, P., Schneider, J. W. (2010). Deviance and medicalization: From badness to sickness. Philadelphia: Temple University Press.

Daniels, N. (1981). Health-Care Needs and Distributive Justice. Philosophy and Public Affairs, 10(2), 146-179

De Galembert, C., Rostaing, C. (2014). Ce que les droits fondamentaux changent à la prison. Présentation du dossier. Droit et société, 87, 291-302

Exworthy, T., Samele, C., Urquìa, N., Forrester, A. (2012). Asserting prisoner's right to health. Progressing beyond equivalence. Psychiatric Services, 63(3), 270-275

Gainotti, S., Petrini, C. (2020). Principio di equivalenza delle cure e il diritto alla salute in ambito carcerario, Mancinelli R., Chiarotti M. e Libianchi S. (eds.). Salute nella polis carceraria: evoluzione della medicina penitenziaria e nuovi modelli operativi. Rapporto ISTISAN-Istituto Superiore di Sanità, 136-144 [online], available: $\quad \mathrm{https} / /$ www.iss.it/documents/20126/45616/19_22_web.pdf/e8fc4e7c-2eb1-9f44-667c$\mathrm{e} 0 \mathrm{a} 048589 \mathrm{c} 8 \mathrm{a} ? \mathrm{t}=1581095896916$ (February 5, 2021)

Gallo, E., Ruggiero, V. (1989). Il carcere immateriale. La detenzione come fabbrica di handicap. Torino: Edizioni Sonda.

Gonin, D. (1991). La santé incarcérée. Medécine et condition de vie en detention. Paris: l'Archipel.

Ingrosso, M., Mascagni, G. (2020). Pratiche e relazioni di cura in ambito sanitario, in Cardano, M., Giarelli, G., Vicarelli, G. (eds.). Sociologia della salute e della medicina, Bologna: Il Mulino, 155-176.

Jotterand, F., Wangmo, T. (2014). The Principle of Equivalence Reconsidered: Assessing the Relevance of the Principle of Equivalence in Prison Medicine. The American Journal of Bioethics, 14(7), 4-12

Lines, R. (2006). From equivalence of standards to equivalence of objectives: The entitlement of prisoners to health care standards higher than those outside prisons. International Journal of Prisoner Health, 2(4), 269280

Mosconi, G. (2005). Il carcere come salubre fabbrica di malattia. Rassegna penitenziaria e criminologica, 1, 5976

Neisser, E. (1977). Is there a doctor in the joint? The search for constitutional standards for prison health care. Virginia Law Review, 63, 921-973

Neri, S., Spina, E., Vicarelli, G. (2020). Le configurazioni mutevoli delle professioni sanitarie, in Cardano, M., Giarelli, G., Vicarelli, G. (eds.), Sociologia della salute e della medicina, Bologna: Il Mulino, 269-294.

Niveau, G. (2007). Relevance and limits of the principle of "equivalence of care" in prison medicine. Journal of Medical Ethics, 33(10), 610-613

Pavarini, M. (2003). Per una penalità sostenibile. Dignitas, 3, 6-14

Pont, J., Stover, H., Wolff, H. (2012). Dual Loyalty in Prison Health Care. Health Policy and Ethics, 102(3), 475-480 
Rawls, J. (1971). A Theory of Justice. Cambridge: Harvard University Press.

Ronco, D. (2018). Cura sotto controllo. Il diritto alla salute in carcere. Roma: Carocci.

Ronco, D. (2014). La salute negata. Processi di esclusione nelle carceri italiane. Studi sulla questione criminale, $3,107-125$

Ronco, D. (2013). Health perception in prison, in C. Mirisola (ed.). All out, all in free. Health in prisons, Rome: INMP.

Ross, M.W., Diamond, P.M. (2008). Measurement of prison social climate: A comparison of an inmate measure in England and the USA. Punishment \& Society, 10, 447-474.

Rusche, G., Kirchheimer, O. (1939). Punishment and Social Structure, New York: Russel \& Russel.

Salle, G., Chantraine, J. (2009). Le droit imprisonnée. Sociologie des usages sociaux du droit en prison. Politix, 22(87), 93-117.

Saponaro, A. (2018). Il corpo incarcerato: l'insalubrità carceraria specchio di una immanente cultura dell'afflittività vendicativa della pena in Italia, Salute e Società, XVII (1), 59-72

Sim, J. (2002). The Future of Prison Health Care: A Critical Analysis. Critical Social Policy, 22 (2), 300-323.

Sim, J. (1990). Medical Powers in Prison: The Prison Medical Service in England 1774-1989, Philadelphia: Open University Press.

Van der Helm, P., Stams, G. J., Van der Laan, P. (2011). Measuring Group Climate in Prison. The Prison Journal, 91, 158-176

Vianello, F. (2018). Norme, codici e condotte: la cultura del penitenziario. Gli attori sociali di fronte alla criticità dell'ambiente carcerario. Sociologia del diritto, 3, 67-85

Whyte, K. L.A., Jordens, C. F. C., Kerridge, I. (2014). Contextualising Professional Ethics: The Impact of the Prison Context on the Practices and Norms of Health Care Practitioners. Bioethical Inquiry, 11, 333-345 